\title{
Virtual Reality Simulation to Help Decrease Stress and Anxiety Feeling for Children during COVID-19 Pandemic
}

\author{
Devi Afriyantari Puspa Putri ${ }^{1}$, Ratri Kusumaningtyas ${ }^{2}$, Tsania Aldi $^{3}$, Fikri Zaki Haiqal ${ }^{4}$ \\ Informatics Engineering Department ${ }^{1,3,4}$ \\ Communication Sciences Department ${ }^{2}$ \\ Universitas Muhammadiyah Surakarta ${ }^{1,2,3,4}$ \\ Surakarta, Indonesia ${ }^{1,2,3,4}$
}

\begin{abstract}
The occurrence of COVID-19 pandemic has changed people's life in every aspect, such as applying social distancing, the transition from offline to online activity are applied in order to decrease and stop the spread of the virus. This sudden change causes a fairly high level of anxiety and stress in society, especially for children because of activity restrictions. Various innovations, especially technology have been carried out to overcome the problems in distance restrictions that have arisen due to the COVID-19 pandemic. Virtual reality believes becoming one of the innovations that can be used to reduced anxiety levels and boredom during activity rectrictions, because it creates an artificial environment for humans to socialize. In this research, combine the Unity3D and blender software to build a virtual reality simulation with the help of virtual glassed to give a real impression of the virtual room that has been created. This VR application consists of three environments that children can use it to explore the virtual room without need being in crowded atmosphere. Based on the result of pretest and posttest questionnaire in $\mathbf{3 0}$ participants with the range age from seven to ten, it concludes that this VR applications can decrease the level of stress and anxiety in children by one to two levels. Besides that, this application located in acceptable area based on SUS score system.
\end{abstract}

Keywords-Blender; COVID-19; Unity3D; virtual reality

\section{INTRODUCTION}

In the last decade, it can be seen that the development of information technology has grown rapidly, and has contributed to advancing world civilization, including the creation of borderless world especially for the access of information. One of the hot topic in tehcnological development field is Virtual Reality ( VR ), which is the creation of a technological simulation resulting from a threedimensional ( $3 \mathrm{D}$ ) environment [1][2]. Along with the development of increasingly advanced technology, there are many changes that occur in the world, one of the remarkable changes is the transfer from all offline activities to online due to the coronavirus disesase 2019 (COVID-19) pandemic.

The COVID-19 pandemic began to emerge at the end of 2019 in the city of Wuhan, Hubei Province, China and began to attract a lot of world attention [3]. Recently, COVID-19 has infected more than 89 million people in 218 countries [4], due to massive transmission cause many countries implementing new regulations to stop the spread of COVID-19. One of the effective way to minimalize the spread of COVID-19 to implement a lockdown which has an impact on restrictions and the closure of public access that has the potential to cause crowds, including : school closures, restrictions on shopping places and tourist attractions. This has a fairly serious impact in all aspects of life [5].

Based on research [6],[7] there are many psychological impacts that have arisen due to the COVID-19 pandemic, including increased levels of anxiety and stress and even more severe effects if people have to undergo self-quarantine. In this era of social restrictions, technological advances are considered to be able to help reduce the negative effects caused by COVID-19, as well as become a solution in the current massive social restrictions. This argument also pointed out in [21] which highligted that digital approaches, such as AR and VR should be optimised in order to help children mental and behaviour during this pandemic era. In line with research [5] that utilizes technological advances to conduct distance learning, or the use of augmented reality (AR) applications as tutorials related to effective hand washing in order to prevent COVID-19 infection [8]. Another research on AR [20] has a conclusion that the use of AR application improve the effectivenes of training while conduct on stressful environment.

In addition, one of the technological advances that can be utilized in overcoming the COVID-19 crisis is the use of VR technology that can help overcome current health problems [9]. In the study [10] discussed the relationship between the use of VR technology that can help reduce pain in children during burn replacement. Several research [19][22] has been conducted, and gain conclusion that VR, and AR have a significant effect to reduce or prevent stress during COVID-19 Pandemic. It is happen because using the virtual tour can generate sense of belonging and affective emotion which lead people able to reduce their stress level. Furthermore, in [12] conclude that VR have a possibility to becoming one of the tools that used in stress-related treatment especially during this pandemic era. However in those research papers which has been published there are very few area which explore to implement VR to reducing strees during Covid-19 for children from seven to ten years. 
Based on this background, to fill the missing link on this research area, author create a VR simulation that focuses on helping children minimize stress and boredom levels during social movement restrictions, which offers four different outdor area. This research is deemed necessary so that children can stay at home and feel comfortable doing activities at home using this application in order to prevent the transmission of COVID-19, whose movement is still very massive and fast. This research is also a form of contribution in technology field which help childrens psychological issues especially during COVID-19.

\section{RELATED WORK}

One of the literatures in this research is related to making learning applications regarding proper hand washing during a pandemic [8]. In this study, the use of AR uses hand movements as a marker and divides the learning process into three stages. The results of this study were 69\% of respondents felt they better understand how to wash their hands properly after seeing this AR application. Another study [11] is a study that focuses on research on the use of VR for children with special needs (ABK) when they have to do rehabilitation at home during the COVID-19 pandemic. This study found that VR technology can be used in children with special needs to maintain and improve their motor function levels during home care. Another study [13] measured the accuracy and effectiveness of using VR as a companion tool for physical exercise in the elderly during the COVID-19 pandemic. The results of this study state that by using VR during the implementation of social restrictions, the elderly can improve motor skills, and can reduce the level of obesity in their body.

Research related to literature studies [14], conducting a review of the role of AR in handling the post-COVID-19 tourism sector, concluded that the role of ICT (Information and communication technology) such as AR, or VR is an innovative application that can be utilized by the tourism sector because it minimizes contact directly and can ensure tourist satisfaction and safety during the COVID-19 pandemic or after the pandemic is over. Another research related to the use of VR was carried out by [12] regarding the development of a VR-based project called MIND-VR which focuses on developing virtual psychoeducational experiences that provide basic information about stress and anxiety disorders in health workers. The results of related studies state that the therapeutic process using VR is more effective than using video. This study also states that further studies related to the implementation of VR to deal with stress and psychological trauma due to the impact of COVID-19 are needed, especially in the use of VR at home, or in the hospitals.

The study in [19] build a VR called "the secret garden" which provide refreshing scenery and calm voice to help people overcome their stress issue related to COVID-19. It took 7 days measurement to reach the conclusion. This research has an objective to reducing stress by improve people's positive emotions using VR application. The result of the research already published in [23] which stated that, even in prelliminary stages, it shows positive impact that VR application can reduces participant stress during COVID-19 especially after two months lockdown. Another study regarding reduce stress during COVID-19 has been implemented in [22] that utilise $360^{\circ}$ virtual tour. The study use VR application to allow participant explore place in $360^{\circ}$ view. This research involves 235 participants and reach conclusion that using virtual tour have a high degree of satisfaction which lead to decreasing their stress level. This research also stated that VR have a contribution to improve people psychological well-being. Beside that, VR also becoming one of the technologies that becoming recommendation to use for people who want to reduce their stress level especially during or after this pandemic era.

Based on several studies that have been discusses, it can be concluded that technology, especially VR have many positive contributions for people live especially during lockdown era. One of the benefits that appeared by using VR can be used to reducing stress level, because sudden change in people daily life. However, there are very few studies about stress levels during this pandemic era which involves children. In fact, children becoming one of the most affected subjects this time, because they cannot play outside and study freely anymore. Based on several studies that have been discussed, to complement previous studies, and complete the missing link, this research has objective to builds a VR application that focuses on reducing and preventing stress in children during the COVID-19 pandemic. In addition to building VR applications, this study also measures the effectiveness of using VR, as well as the usefullnes of this application.

\section{The Proposed Method}

In this research, agile methodology has been choosed to develop the application. Even though according to [24] waterfall model still become the most commonly used in software development. It has lack of flexibility when major changes are happened [25]. Therefore, this research decides to use agile methodology which offer much flexibility of design changes in the future and offers faster release compare to the traditional one [25]. In addition, based on Fig. 1 before implementation process done, the whitebox and blackbox testing are carried out to make sure that VR application already meet the requirement.

The whole process of build a VR application can be seen in Fig. 1 and 2. In Fig. 1 showed the flow of VR application development, while Fig. 2 shows the overall research flow.

In Fig. 1, the research begins by analyzing the needs needed in the software and hardware sections including Unity3D, Oculus, and VR glasses. The application design stage consists of making storyboards, interface designs as well as terrain and environment assets that are created using blender and unity3D software. The programming process for building this VR application uses the default language of the Unity 3D software, namely C\# which is assisted by visual programming on Playmaker assets. After the coding process is complete, it will be combined with various assets and 3D designs that have been built, then the rendering process is carried out. This process using the target API level 30 on the android system, and it is necessary to install the VR Google SDK for unity, as well as the VR headset that will be used. Before implementing the application, a testing process is 
carried out using blackbox and whitebox tests [16] to ensure the application runs well. The next process is to do a demo to participants using the help of goggle glass to run VR applications. The overall research flow in the implementation process can be seen in Fig. 2.

In this study, as shown in Fig. 2, prior to do VR app implementations, participants were pretested first to determine the level of depression experienced using a "nine-symptom checklist" questionnaire [15] which divided the severity into 5 parts, namely:

- Minimal : scor $1-4$

- Mild : scor $5-9$

- Moderate : scor $10-14$

- Moderately Severe : scor 15 - 19

- Severe : Scor 20 - 27

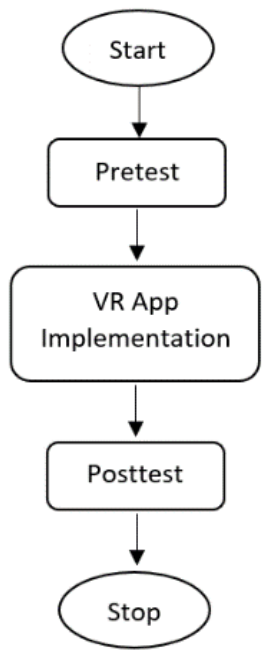

Fig. 2. VR Research Flow.

TABLE I. NINE SYMPTOM CHECKLISTS

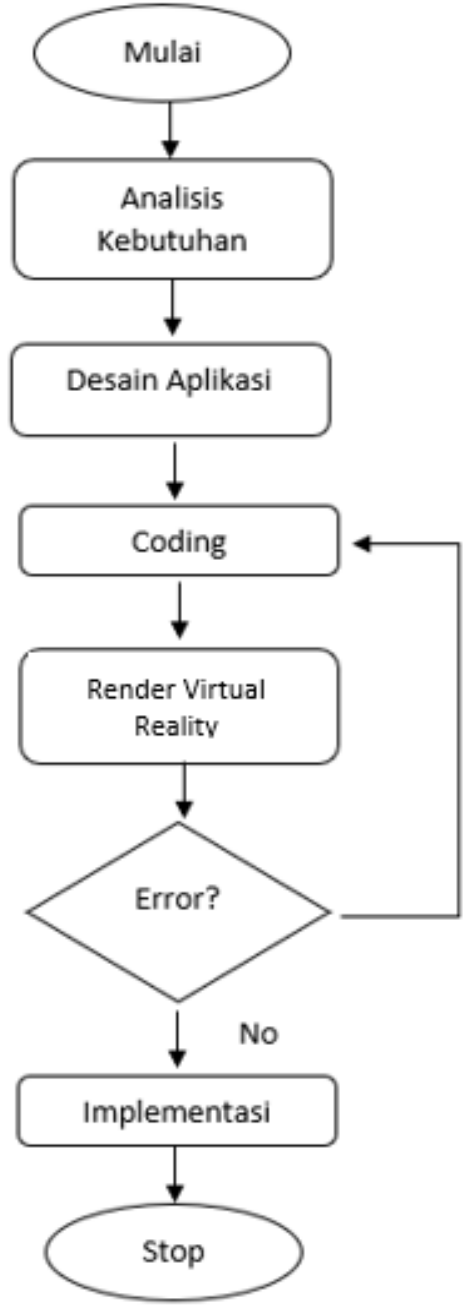

Fig. 1. VR Application Development Flow.
Yes

\begin{tabular}{|c|c|c|c|c|c|}
\hline No & $\begin{array}{l}\text { Over the last } 2 \text { weeks, } \\
\text { how often have you been } \\
\text { bothered by any of the } \\
\text { following problems? }\end{array}$ & $\begin{array}{l}\text { Not } \\
\text { all }\end{array}$ & $\begin{array}{l}\text { Severa } \\
\text { I Days }\end{array}$ & $\begin{array}{l}\text { More } \\
\text { than } \\
\text { half } \\
\text { the } \\
\text { days }\end{array}$ & $\begin{array}{l}\text { Nearly } \\
\text { every } \\
\text { day }\end{array}$ \\
\hline 1 & $\begin{array}{l}\text { Little interest or pleasure in } \\
\text { doing things? }\end{array}$ & 0 & 1 & 2 & 3 \\
\hline 2 & $\begin{array}{l}\text { Feeling down, depressed, } \\
\text { or hopeless? }\end{array}$ & 0 & 1 & 2 & 3 \\
\hline 3 & $\begin{array}{l}\text { Trouble falling or staying } \\
\text { asleep, or sleeping too } \\
\text { much? }\end{array}$ & 0 & 1 & 2 & 3 \\
\hline 4 & $\begin{array}{l}\text { Feeling tired or having } \\
\text { little energy? }\end{array}$ & 0 & 1 & 2 & 3 \\
\hline 5 & $\begin{array}{l}\text { Poor appetite or } \\
\text { overeating? }\end{array}$ & 0 & 1 & 2 & 3 \\
\hline 6 & $\begin{array}{l}\text { Feeling bad about yourself } \\
\text { - or that you are a failure or } \\
\text { have let yourself or your } \\
\text { family down? }\end{array}$ & 0 & 1 & 2 & 3 \\
\hline 7 & $\begin{array}{l}\text { Trouble concentrating on } \\
\text { things, such as reading the } \\
\text { newspaper or watching } \\
\text { television? }\end{array}$ & 0 & 1 & 2 & 3 \\
\hline 8 & $\begin{array}{l}\text { Moving or speaking so } \\
\text { slowly that other people } \\
\text { could have noticed? Or the } \\
\text { opposite - being so fidgety } \\
\text { or restless that you have } \\
\text { been moving around a lot } \\
\text { more than usual? }\end{array}$ & 0 & 1 & 2 & 3 \\
\hline 9 & $\begin{array}{l}\text { Thoughts that you would } \\
\text { be better off dead, or of } \\
\text { hurting yourself in some } \\
\text { way? }\end{array}$ & 0 & 1 & 2 & 3 \\
\hline
\end{tabular}


The details of the "nine symptom checklists" questionnaire can be seen in Table I. This patient health questionnaire-9 (PHQ-9) is a recommendation to use as a self-measurement test to detect the rate of depression that consists from 0 to 3 level [26]. The primary reason this screening questionnaire has been chosed because it offers the ease of use the nine set of question. The ease of use the tools become the primary concern in this research because the subject that will be tested are children with has range of age from seven to ten. Beside the easiness, previous study which already used this PHQ-9 showed the accuracy screening using the nine set questions and the test also falled in acceptable area which obtain sensitifity around 0.84 and specifity about 0.77 [27]. Another reasearch that conducted in [28] showed a good sensitivy and specificity which fall below 0.83 , and 0.72 respectively, using this PHQ-9 questionnaire does not necessary to divide the participants based on their gender. According to several reaseraches that already done which showed acceptable examination, it makes author believe that using this tools lead to the accurate results.

During the posttest stage, the same questionnaire table was used as already done in the pretest conditions, which aims to measure whether there is a positive impact obtained by respondents after using the VR application.

TABLE II. SUS LIST OF QUESTIONS

\begin{tabular}{|c|c|c|c|c|c|c|}
\hline \multirow[t]{2}{*}{ No } & \multirow[t]{2}{*}{ Questions } & \multirow{2}{*}{$\begin{array}{l}\text { Strongly } \\
\text { Disagree }\end{array}$} & & & & \multirow{2}{*}{$\begin{array}{l}\text { Strongly } \\
\text { Agree }\end{array}$} \\
\hline & & & 2 & 3 & 4 & \\
\hline 1 & $\begin{array}{l}\text { I think that I would like to } \\
\text { use this system frequently. }\end{array}$ & & & & & \\
\hline 2 & $\begin{array}{l}\text { I found the system } \\
\text { unnecessarily complex. }\end{array}$ & & & & & \\
\hline 3 & $\begin{array}{l}\text { I thought the system was } \\
\text { easy to use. }\end{array}$ & & & & & \\
\hline 4 & $\begin{array}{l}\text { I think that I would need the } \\
\text { support of a technical } \\
\text { person to be able to use this } \\
\text { system. }\end{array}$ & & & & & \\
\hline 5 & $\begin{array}{l}\text { I found the various } \\
\text { functions in this system } \\
\text { were well integrated. }\end{array}$ & & & & & \\
\hline 6 & $\begin{array}{l}\text { I thought there was too } \\
\text { much inconsistency in this } \\
\text { system }\end{array}$ & & & & & \\
\hline 7 & $\begin{array}{l}\text { I would imagine that most } \\
\text { people would learn to use } \\
\text { this system very quickly. }\end{array}$ & & & & & \\
\hline 8 & $\begin{array}{l}\text { I found the system very } \\
\text { cumbersome to use }\end{array}$ & & & & & \\
\hline 9 & $\begin{array}{l}\text { I felt very confident using } \\
\text { the system }\end{array}$ & & & & & \\
\hline 10 & $\begin{array}{l}\text { I needed to learn a lot of } \\
\text { things before I could get } \\
\text { going with this system }\end{array}$ & & & & & \\
\hline
\end{tabular}

In addition, another test called System Usablitiy Scale (SUS) also carried out in order to measure the usefullnes of the application [17]. According to [29] SUS is one of the most tests that used to measure the perceive ussability and still remain relevant in the future. Based on those two researchers explain in the beginning, this SUS test is necessary to be done to meet the objectives in this research as written in Section 2. The details questioned of SUS can be seen in Table II, which have five scale, from the highest point (strongly agree) to the lowest point (strongly disagree).

\section{RESUlt AND Discussion}

Based on the research flow in Section 3, the VR simulation application was built by adding the required assets, including Google Cardboard, Asset Image and Google VR SDK in Unity. One of the processes of making VR in unity3D can be seen in set collection of workspaces in Fig. 3a, 3b, 3c, and 3d.

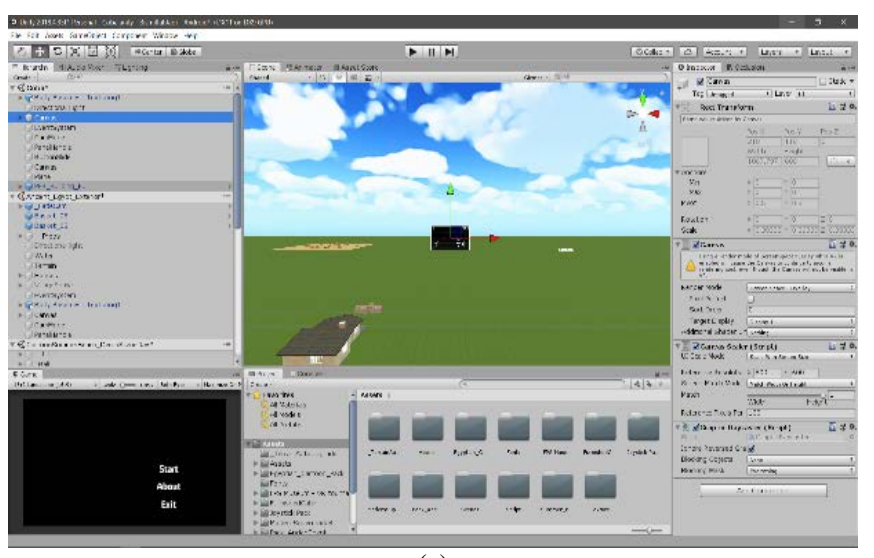

(a)

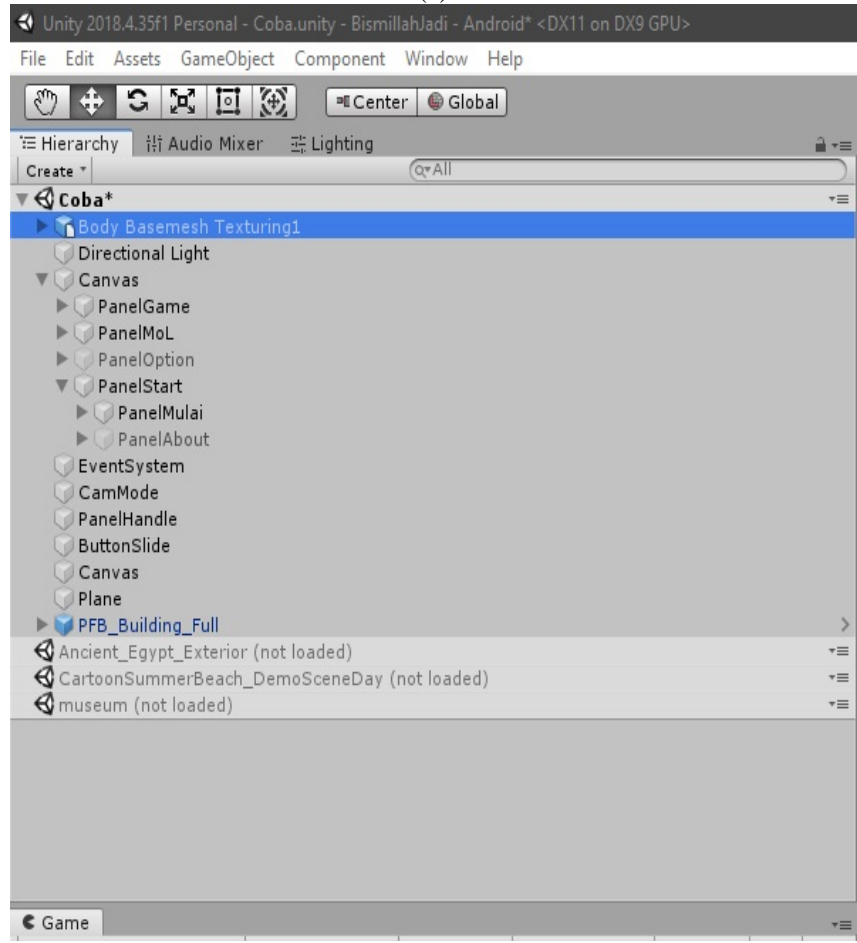

(b) 


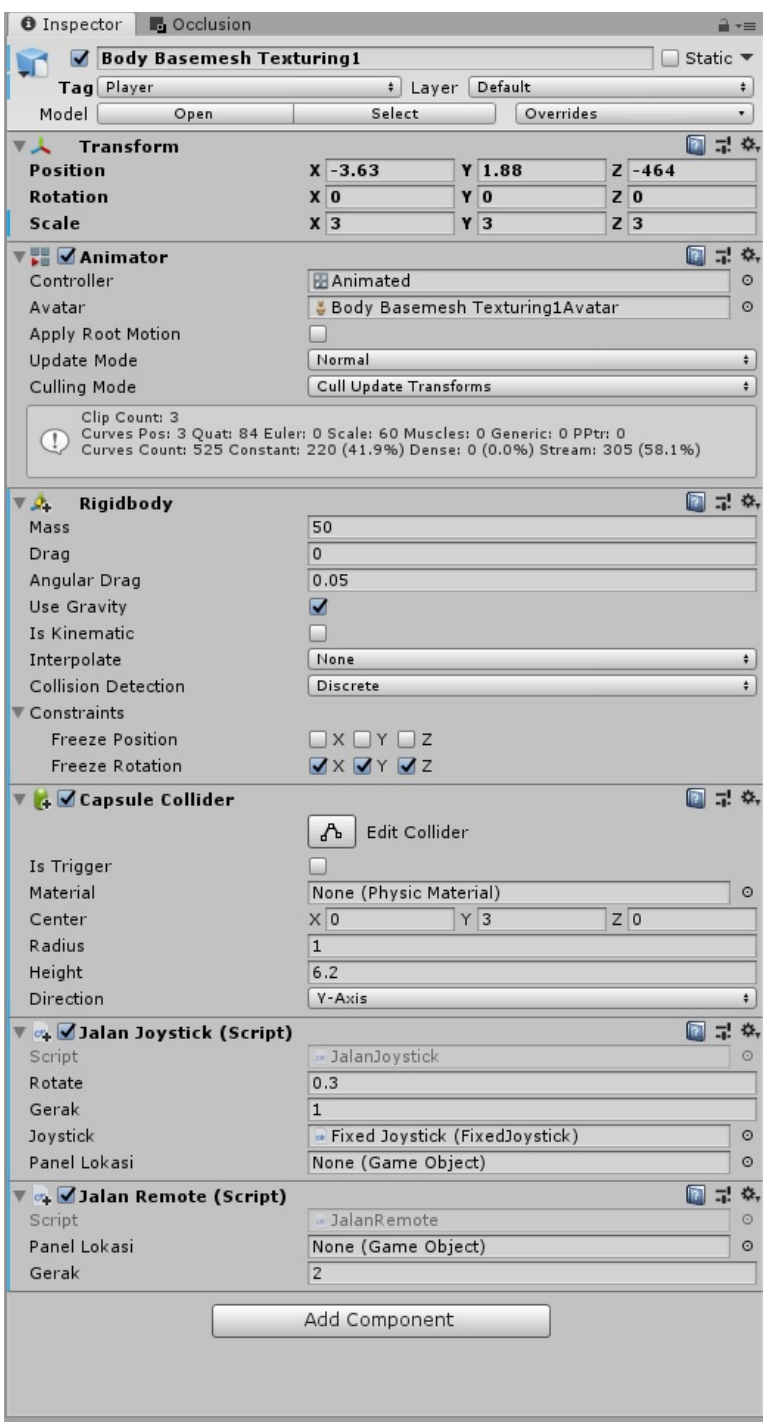

(c)

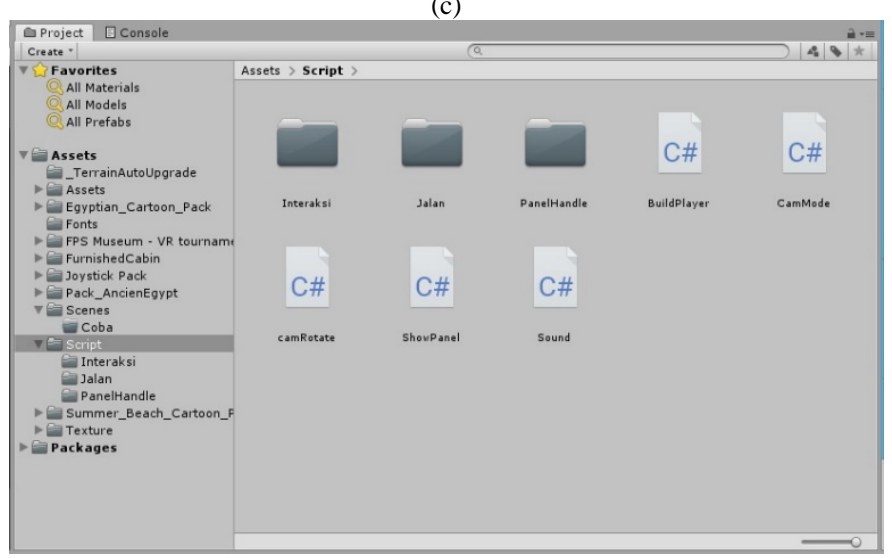

(d)

Fig. 3. (a) Whole Sample Image Process VR Development in Unity3D, (b) Hierarchy Page in Unity3D, (c) Inspector Page in Unity3D, (d) Project Struct.Ure in Unity3D.

In this VR application consists of four different scenes, namely: houses, beaches, Egypt and museums. The scene switching process is made using C\# code, the snipped code of it process can be seen in Fig. 4.

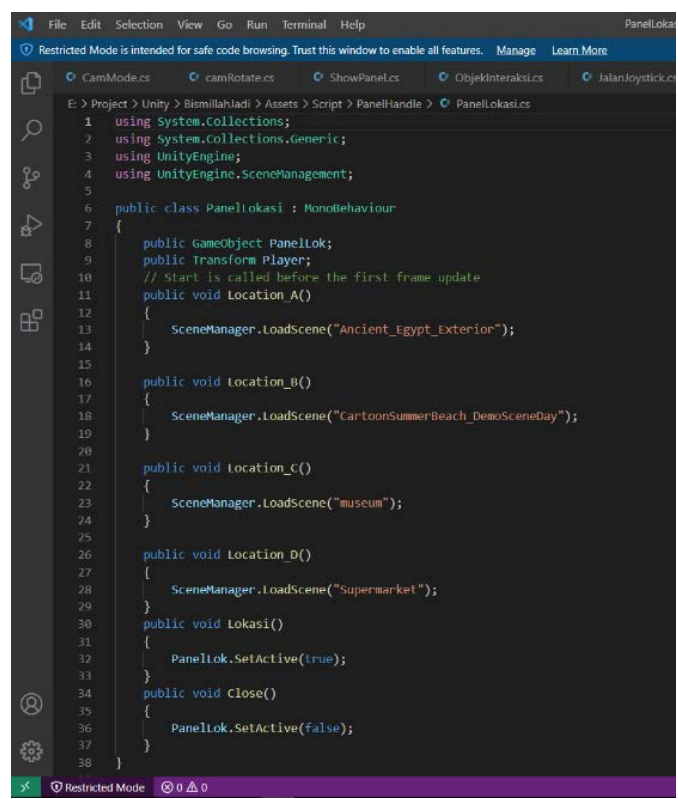

Fig. 4. Snipped Code C\# for Switching Each Scene.

The final results of the VR application in this study are presented in Fig. 5, and 6 which are images based on the participants point of view when viewed using VR glasses.

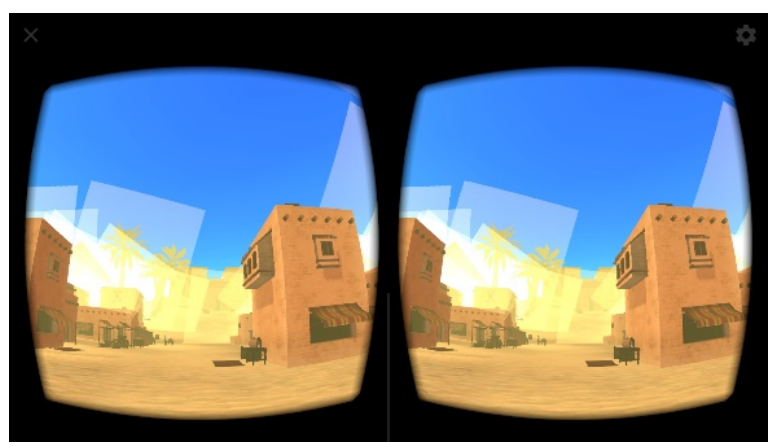

Fig. 5. Sample Application VR Views 1.

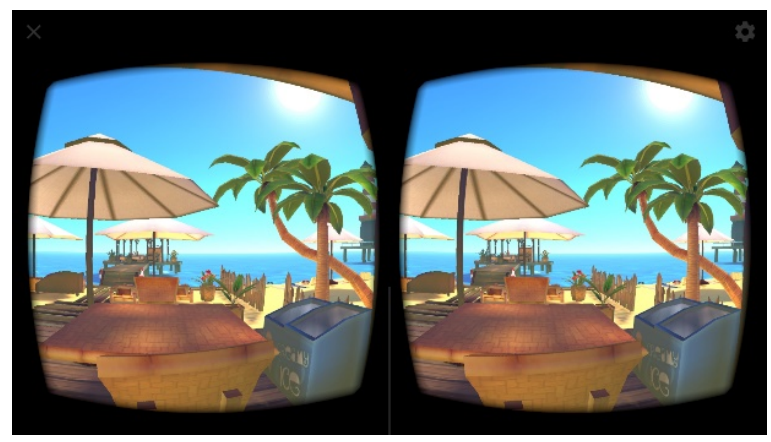

Fig. 6. Sample Application VR Views 2.

Before the application is used, as described in Section 3, blackbox and whitebox tests are carried out. The whitebox test is done by testing the program code of this application to make sure that no flaws appeared and the code written clearly. Afterwards, the blackbox testing perform to make sure all of the functionalities perform well. The overall results of blackbox testing can be seen in Table III. 
TABLE III. RESULT OF BLACKBOX TEST

\begin{tabular}{|c|c|c|c|c|}
\hline No & Test Class & $\begin{array}{l}\text { Scenario } \\
\text { Testing }\end{array}$ & Expected & $\begin{array}{l}\text { Resul } \\
\text { ts }\end{array}$ \\
\hline 1 & Start Menu & $\begin{array}{l}\text { Pressing the } \\
\text { Star Button }\end{array}$ & $\begin{array}{l}\text { Displays a selection of } \\
\text { VR mode and Mobile } \\
\text { Mode }\end{array}$ & Valid \\
\hline 2 & $\begin{array}{l}\text { About } \\
\text { Menu }\end{array}$ & $\begin{array}{l}\text { Pressing about } \\
\text { button }\end{array}$ & Displays about page & Valid \\
\hline 3 & Exit Menu & $\begin{array}{l}\text { Pressing the exit } \\
\text { button }\end{array}$ & Exit the VR application & Valid \\
\hline \multirow[t]{3}{*}{4} & $\begin{array}{l}\text { Mobile } \\
\text { Mode } \\
\text { Menu } \\
\end{array}$ & $\begin{array}{l}\text { Pointing the } \\
\text { joystick right } \\
\text { and left }\end{array}$ & $\begin{array}{l}\text { Displays the appropriate } \\
\text { direction with the } \\
\text { joystick }\end{array}$ & Valid \\
\hline & & $\begin{array}{l}\text { Pressing the } \\
\text { Settings button }\end{array}$ & Displays the setting page & Valid \\
\hline & & $\begin{array}{l}\text { Pressing Map } \\
\text { button }\end{array}$ & $\begin{array}{l}\text { Display various maps } \\
\text { option }\end{array}$ & Valid \\
\hline \multirow[t]{3}{*}{5} & Map Menu & $\begin{array}{l}\text { Pressing Egypt } \\
\text { choice }\end{array}$ & $\begin{array}{l}\text { Display Egypt } \\
\text { Environment }\end{array}$ & Valid \\
\hline & & $\begin{array}{l}\text { Pressing Beach } \\
\text { choice }\end{array}$ & $\begin{array}{l}\text { Display Beach } \\
\text { Environment }\end{array}$ & Valid \\
\hline & & $\begin{array}{l}\text { Pressing } \\
\text { museum choice }\end{array}$ & $\begin{array}{l}\text { Display Museum } \\
\text { Environment }\end{array}$ & Valid \\
\hline \multirow[t]{4}{*}{6} & $\begin{array}{l}\text { Egypt, } \\
\text { Beach, and } \\
\text { Museum } \\
\text { Menu }\end{array}$ & $\begin{array}{l}\text { Pressing the } \\
\text { Back Button }\end{array}$ & $\begin{array}{l}\text { Displays two choices } \\
\text { menus are VR and } \\
\text { mobile mode }\end{array}$ & Valid \\
\hline & & $\begin{array}{l}\text { Pressing setting } \\
\text { button }\end{array}$ & Display setting page & Valid \\
\hline & & $\begin{array}{l}\text { Pressing Map } \\
\text { btton }\end{array}$ & $\begin{array}{l}\text { Display various map } \\
\text { choices }\end{array}$ & Valid \\
\hline & & $\begin{array}{l}\text { Pointing the } \\
\text { joystick right } \\
\text { and left }\end{array}$ & $\begin{array}{l}\text { Displays the appropriate } \\
\text { direction with the } \\
\text { joystick }\end{array}$ & Valid \\
\hline
\end{tabular}

After passing the two functionality tests, the application was tested on 30 child respondents with an age range of 7-10 years which held with parental assistance using strict covid-19 protocol. In the process of testing the level of anxiety and SUS, parental assistance is necessary to obtain valid test results. The results of the comparison of pretest and posttest can be seen in Fig. 7. It can be seen that most of the children has obtain lower level of stress after used VR application.

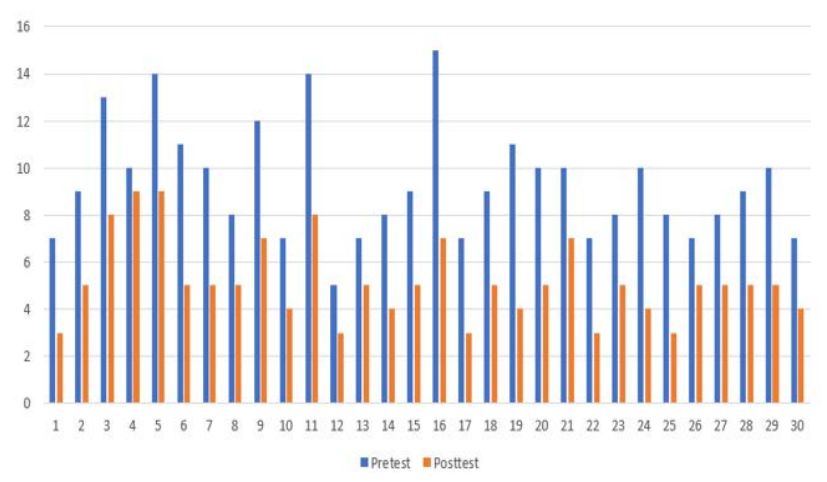

Fig. 7. Pretest and Posttest Results after Application Testing.
TABLE IV. RESULT OF SUS QUESTIONNAIRE

\begin{tabular}{|c|c|c|c|c|c|c|c|c|c|c|c|c|}
\hline \multirow{2}{*}{$\begin{array}{l}\text { Respond } \\
\text { en }\end{array}$} & \multicolumn{10}{|c|}{ Result of SUS Score } & \multirow{2}{*}{$\begin{array}{l}\text { Tota } \\
1\end{array}$} & \multirow{2}{*}{$\begin{array}{l}\text { Final } \\
\text { Score }\end{array}$} \\
\hline & 1 & 2 & 3 & 4 & 5 & 6 & 7 & 8 & 9 & $\begin{array}{l}1 \\
0\end{array}$ & & \\
\hline 1 & 3 & 3 & 3 & 2 & 3 & 3 & 3 & 3 & 3 & 2 & 28 & 70 \\
\hline 2 & 4 & 4 & 4 & 4 & 4 & 4 & 3 & 3 & 4 & 2 & 36 & 90 \\
\hline 3 & 4 & 4 & 3 & 3 & 4 & 3 & 2 & 4 & 4 & 2 & 33 & 82.5 \\
\hline 4 & 4 & 2 & 3 & 2 & 4 & 3 & 3 & 2 & 4 & 2 & 29 & 72.5 \\
\hline 5 & 4 & 3 & 4 & 3 & 4 & 4 & 2 & 3 & 4 & 4 & 35 & 87.5 \\
\hline 6 & 4 & 4 & 3 & 3 & 4 & 3 & 4 & 4 & 4 & 2 & 35 & 87.5 \\
\hline 7 & 4 & 3 & 3 & 4 & 3 & 2 & 2 & 2 & 4 & 2 & 29 & 72.5 \\
\hline 8 & 3 & 3 & 3 & 3 & 3 & 3 & 3 & 2 & 4 & 2 & 29 & 72.5 \\
\hline 9 & 4 & 3 & 3 & 4 & 4 & 3 & 3 & 4 & 3 & 2 & 33 & 82.5 \\
\hline 10 & 4 & 3 & 3 & 3 & 4 & 2 & 3 & 3 & 4 & 3 & 32 & 80 \\
\hline 11 & 3 & 3 & 4 & 3 & 3 & 2 & 4 & 3 & 3 & 2 & 30 & 75 \\
\hline 12 & 4 & 3 & 3 & 2 & 4 & 3 & 3 & 2 & 3 & 3 & 30 & 75 \\
\hline 13 & 4 & 4 & 3 & 3 & 3 & 2 & 3 & 3 & 4 & 4 & 33 & 82.5 \\
\hline 14 & 4 & 3 & 3 & 3 & 4 & 4 & 3 & 2 & 4 & 2 & 32 & 80 \\
\hline 15 & 4 & 3 & 3 & 4 & 2 & 4 & 3 & 3 & 3 & 2 & 31 & 77.5 \\
\hline 16 & 3 & 3 & 3 & 3 & 4 & 4 & 4 & 4 & 4 & 3 & 35 & 87.5 \\
\hline 17 & 4 & 3 & 3 & 4 & 3 & 4 & 4 & 4 & 3 & 3 & 35 & 87.5 \\
\hline 18 & 4 & 3 & 3 & 2 & 4 & 3 & 3 & 2 & 4 & 3 & 31 & 77.5 \\
\hline 19 & 4 & 3 & 3 & 3 & 3 & 2 & 3 & 2 & 4 & 2 & 29 & 72.5 \\
\hline 20 & 3 & 3 & 3 & 3 & 3 & 2 & 3 & 3 & 3 & 2 & 28 & 70 \\
\hline 21 & 4 & 4 & 3 & 2 & 3 & 3 & 3 & 2 & 4 & 4 & 32 & 80 \\
\hline 22 & 4 & 4 & 3 & 3 & 3 & 3 & 4 & 3 & 4 & 2 & 33 & 82.5 \\
\hline 23 & 4 & 4 & 4 & 4 & 4 & 4 & 4 & 3 & 3 & 3 & 37 & 92.5 \\
\hline 24 & 3 & 3 & 3 & 2 & 4 & 3 & 3 & 2 & 4 & 3 & 30 & 75 \\
\hline 25 & 4 & 4 & 3 & 3 & 3 & 3 & 2 & 4 & 4 & 3 & 33 & 82.5 \\
\hline 26 & 3 & 3 & 4 & 4 & 4 & 3 & 3 & 2 & 4 & 2 & 32 & 80 \\
\hline 27 & 4 & 4 & 3 & 3 & 2 & 3 & 2 & 3 & 4 & 4 & 32 & 80 \\
\hline 28 & 3 & 4 & 4 & 3 & 4 & 4 & 3 & 2 & 4 & 3 & 34 & 85 \\
\hline 29 & 4 & 4 & 3 & 2 & 4 & 4 & 3 & 2 & 4 & 3 & 33 & 82.5 \\
\hline 30 & 3 & 3 & 3 & 2 & 4 & 3 & 3 & 2 & 4 & 3 & 30 & 75 \\
\hline average & & & & & & & & & & & & 79.91 \\
\hline
\end{tabular}

Based on the results of the pretest and posttest, it can be seen that before implementing VR application, most of respondents experienced depression in the mild and moderate ranges, there was only one respondent who was in moderately severe condition. However, after the respondent was given a VR application to get a new atmosphere of exploring several virtual places, it can be seen that there was a significant decrease in stress and anxiety levels, which can be seen in the survey results listed in Fig. 7. Based on Fig. 7, it can be seen that most of the respondents experienced decrease in anxiety level, about one level lower compare to pretest result. According on the results of the posttest respondents 
experienced anxiety at a minimal and mild level. In order to measure the usability of the application, SUS questionaire in Table II already performed which use 30 respondents as subjects. The result of SUS testing can be seen in Table IV.

Based on the result shown in Table IV, it can be concluded that the average SUS score obtainend in this VR application around 79.91. It is located in acceptable area, between good and excellent adjective rating in SUS scoring system [18] and can be conclude that this application considered to be useful enough in order to show VR application.

\section{CONCLUSION AND FUTURE WORK}

Based on the results obtained in Section 4, it can be concluded that this VR application has a contribution in reducing the level of anxiety and stress in children during the Covid-19 pandemic as evidenced by the results of the pretest and posttest presented in Fig. 7. Beside that, this VR application has a good adjective ratings SUS based on Table IV. Those two results that achieved in Section four already answer the objective which already discussed in Section two in this research, are to build VR application which allow reduce stress for children and measure the usefulness and effectiveness this application using SUS measurement.

However, many future works are needed to do in order to increase the usefullnes of this applicaion in society. One of challenges that need to tackle in this application are the addition of features to interacts in every scene so children can explore many things while enjoying the virtual environment. Beside that, the education about Covid-19 knowledge also relevant to be added in the future.

\section{ACKNOWLEDGMENT}

This research is fully funded by Hibah Integrasi Tridharma (HIT) Universitas Muhammadiyah Surakarta under the grant number 004/A3.III/FKI/I/2021.

\section{REFERENCES}

[1] Jung, Timothy, M. Claudia tom Dieck, Hyunae Lee, and Namho Chung. "Effects of virtual reality and augmented reality on visitor experiences in museum." In Information and communication technologies in tourism, pp. 621-635. Springer, Cham, 2016.

[2] Putra, Ghali Adyo, Rinta Kridalukmana, and Kurniawan Teguh Martono. "Pembuatan simulasi 3D virtual reality berbasis Android sebagai alat bantu terapi acrophobia." Jurnal Teknologi dan Sistem Komputer 5, no. 1, pp. 29-36, 2017.

[3] Zhai, Yusen, and Xue Du. "Mental health care for international Chinese students affected by the COVID-19 outbreak." The Lancet Psychiatry 7, no. 4: e22, 2020.

[4] Worldometers.info. "COVID-19 Coronavirus Pandemic," Worldometer, Dover Delaware, U.S.A, accessed 09 Januari, 2021.

[5] Qiu, Hanqin, Qinghui Li, and Chenxi Li. "How technology facilitates tourism education in COVID-19: case study of nankai University." Journal of Hospitality, Leisure, Sport \& Tourism Education. p. 100288, 2020.

[6] Wang, Cuiyan, Riyu Pan, Xiaoyang Wan, Yilin Tan, Linkang Xu, Cyrus S. Ho, and Roger C. Ho. "Immediate psychological responses and associated factors during the initial stage of the 2019 coronavirus disease (COVID-19) epidemic among the general population in China." International journal of environmental research and public health 17, no. 5, pp. 1729, 2020.

[7] Brooks, Samantha K., Rebecca K. Webster, Louise E. Smith, Lisa Woodland, Simon Wessely, Neil Greenberg, and Gideon James Rubin.
"The psychological impact of quarantine and how to reduce it: rapid review of the evidence." The Lancet, 2020.

[8] Hanafi, Hafizul Fahri, Mohd Helmy Abd Wahab, Kung-Teck Wong, Abu Zarrin Selamat, Muhamad Hariz Muhamad Adnan, and Fatin Hana Naning. "Mobile augmented reality hand wash (MARHw): mobile application to guide community to ameliorate handwashing effectiveness to oppose Covid-19 disease." International Journal of Integrated Engineering 12, no. 5, pp. 217-223, 2020.

[9] Singh, Ravi Pratap, Mohd Javaid, Ravinder Kataria, Mohit Tyagi, Abid Haleem, and Rajiv Suman. "Significant applications of virtual reality for COVID-19 pandemic." Diabetes \& Metabolic Syndrome: Clinical Research \& Reviews, 2020.

[10] Hua, Yun, Rong Qiu, Wen-yan Yao, Qin Zhang, and Xiao-li Chen. "The effect of virtual reality distraction on pain relief during dressing changes in children with chronic wounds on lower limbs." Pain Management Nursing 16, no. 5, pp. 685-691, 2015.

[11] Demers, Marika, Ophélie Martinie, Carolee Winstein, and Maxime T. Robert. "Active Video Games and Low-Cost Virtual Reality: An Ideal Therapeutic Modality for Children With Physical Disabilities During a Global Pandemic." Frontiers in Neurology 11, pp. 1737, 2020.

[12] Imperatori, Claudio, Antonios Dakanalis, Benedetto Farina, Federica Pallavicini, Fabrizia Colmegna, Fabrizia Mantovani, and Massimo Clerici. "Global Storm of Stress-Related Psychopathological Symptoms: a brief overview on the usefulness of virtual reality in facing the mental health impact of COVID-19." Cyberpsychology, Behavior, and Social Networking 23, no. 11 pp. 782-788, 2020.

[13] Gao, Zan; Lee, Jung E.; McDonough, Daniel J.; Albers, Callie. "Virtual Reality Exercise as a Coping Strategy for Health and Wellness Promotion in Older Adults during the COVID-19 Pandemic" J. Clin. Med. 9, no. 6: 1986, 2020.

[14] Mohanty, Priyakrushna, Azizul Hassan, and Erdogan Ekis. "Augmented reality for relaunching tourism post-COVID-19: socially distant, virtually connected." Worldwide Hospitality and Tourism Themes, 2020.

[15] Kroenke, K., Spitzer, R.L. and Williams, J.B., 2001. The PHQ-9: validity of a brief depression severity measure. Journal of general internal medicine, 16(9), pp.606-613.

[16] Nidhra, S., \& Dondeti, J. (2012). Black box and white box testing techniques-a literature review. International Journal of Embedded Systems and Applications (IJESA), 2(2), 29-50.

[17] Brooke, J., 1996. SUS-A quick and dirty usability scale. Usability evaluation in industry, 189(194), pp.4.

[18] Bangor, Aaron; Kortum, Philip T.; Miller, James T. 2008. An Empirical Evaluation of the System Usability Scale. International Journal of Human-Computer Interaction, 24(6), pp.574-594.

[19] Riva, G., Bernardelli, L., Browning, M.H., Castelnuovo, G., Cavedoni, S., Chirico, A., Cipresso, P., de Paula, D.M.B., Di Lernia, D., Fernández-Álvarez, J. and Figueras-Puigderrajols, N., 2020. COVID feel good-an easy self-help virtual reality protocol to overcome the psychological burden of coronavirus. Frontiers in Psychiatry, 11, p.996.

[20] Razeghi, S., Alipour, S. and Sabet, A., 2021. Enhancing stress management training and communication skills of nursing students during COVID-19 pandemic based on augmented reality. Journal of Modern Medical Information Sciences, 7(1), pp.38-47.

[21] Ye, J., 2020. Pediatric mental and behavioral health in the period of quarantine and social distancing with COVID-19. JMIR pediatrics and parenting, 3(2), p.e19867.

[22] Yang, T., Lai, I.K.W., Fan, Z.B. and Mo, Q.M., 2021. The impact of a $360^{\circ}$ virtual tour on the reduction of psychological stress caused by COVID-19. Technology in Society, 64, p.101514.

[23] Riva, G., Bernardelli, L., Castelnuovo, G., Di Lernia, D., Tuena, C., Clementi, A., Pedroli, E., Malighetti, C., Sforza, F., Wiederhold, B.K. and Serino, S., 2021. A Virtual Reality-Based Self-Help Intervention for Dealing with the Psychological Distress Associated with the COVID-19 Lockdown: An Effectiveness Study with a Two-Week FollowUp. International journal of environmental research and public health, 18(15), p.8188.

[24] Vijayasarathy, L. and Butler, C., Choice of Software Development Methodologies. IEEE Software, pp.0740-7459. 
[25] Al-Saqqa, S., Sawalha, S. and AbdelNabi, H., 2020. Agile Software Development: Methodologies and Trends. International Journal of Interactive Mobile Technologies, 14(11).

[26] Manea, L., Gilbody, S. and McMillan, D., 2015. A diagnostic metaanalysis of the Patient Health Questionnaire-9 (PHQ-9) algorithm scoring method as a screen for depression. General hospital psychiatry, 37(1), pp.67-75.
[27] Lotrakul, M., Sumrithe, S. and Saipanish, R., 2008. Reliability and validity of the Thai version of the PHQ-9. BMC psychiatry, 8(1), pp.1-7.

[28] Beard, C., Hsu, K.J., Rifkin, L.S., Busch, A.B. and Björgvinsson, T., 2016. Validation of the PHQ-9 in a psychiatric sample. Journal of Affective Disorders, 193, pp.267-273.

[29] Lewis, J.R., 2018. The system usability scale: past, present, and future. International Journal of Human-Computer Interaction, 34(7), pp.577-590. 